\title{
EPISTAXIS: ETIOLOGICAL PROFILE AND TREATMENT OUTCOME IN A TEACHING HOSPITAL OF NORTH EASTERN STATE OF SIKKIM, INDIA
}

\author{
Santosh Prasad Kesari , Laiphrakpam Manshi Singh2, Priyadarsini T³, Deepshikha Mishra4
}

${ }^{1}$ Associate Professor, Department of ENT, Sikkim Manipal Institute of Medical Sciences, Gangtok, Sikkim, India.

${ }_{2}^{2}$ MBBS Student, Sikkim Manipal Institute of Medical Sciences, Gangtok, Sikkim, India.

${ }_{3}^{3}$ Postgraduate Trainee, Sikkim Manipal Institute of Medical Sciences, Gangtok, Sikkim, India.

${ }^{4}$ Postgraduate Trainee, Sikkim Manipal Institute of Medical Sciences, Gangtok, Sikkim, India.

\begin{tabular}{l}
\hline ABSTRACT \\
BACKGROUND \\
Epistaxis is defined as bleeding from nostril, nasal cavity or nasopharynx, with the incidence of 30 to $100 /$ lakh. It has been classified \\
into anterior and posterior epistaxis, depending on the site of origin. There are a variety of causes for epistaxis with trauma being \\
the most common in young age and systemic disease in the elderly. The condition can be treated with both conservative and surgical \\
approach. There is a large no of studies on epistaxis from all around the world; however, very few studies from the northeastern part \\
of India. This study is unique at it is carried in a population of high altitude with tough climatic condition.
\end{tabular}

\section{METHODS}

A cross sectional observational study was carried out in Dept. of ENT and casualty with a sample size of 100 . All patients with epistaxis who consented to take part were meticulously interviewed, examined for the site of bleed. Routine blood examination and interdepartmental consultation were done. The data collected was compiled and analyzed using SPSS 16.00.

\section{RESULTS}

Out of 100 patients, 57 were male and 43 were female, with a high incidence in the terms of percentage young age group. The various parameter was compared and analyzed.

\section{CONCLUSIONS}

Epistaxis is common in the young age group with trauma being the most common cause. More such studies should be carried out in this region by taking the climatic condition into consideration to generalize the result to the entire population.

\section{KEY WORDS}

Epistaxis, Trauma, Anterior Nasal Bleed, Hypertension

HOW TO CITE THIS ARTICLE: Kesari SP, Singh LM, Priyadarsini T, et al. Epistaxis: etiological profile and treatment outcome in a teaching hospital of north eastern state of Sikkim, India. J. Evolution Med. Dent. Sci. 2019;8(28):2234-2238, DOI: $10.14260 /$ jemds/2019/489

\section{BACKGROUND}

The term Epistaxis was coined by William Cullen.(1) It is defined as bleeding from nostril, nasal cavity or nasopharynx.(2) It is one of the most common Ear Nose \& Throat ( ENT) emergencies, around $60 \%$ of the population have at least one episode of nose bleeding in their lifetime and $6 \%$ of them need medical attention. ${ }^{3,4)}$ The incidence of Epistaxis ranging from 30 to 100 per 1 lakh every year.(4) Epistaxis is classified into anterior and posterior epistaxis, depending upon the place of origin. Anterior epistaxis arises from damage to Kiesselbach's plexus on the lower portion of anterior nasal septum known as the little's area and it comprises of $80 \%$ of the cases.(4) Epistaxis in the posterior chamber arises from the woodruff's plexus. (1)

'Financial or Other Competing Interest': None.

Submission 23-05-2019, Peer Review 29-06-2019,

Acceptance 05-07-2019, Published 15-07-2019.

Corresponding Author:

Dr. Santosh Prasad Kesari,

Associate Professor,

Department of ENT,

Central Referral Hospital,

SMIMS, $5^{\text {th }}$ Mile, Tadong,

Gangtok, Sikkim, India.

E-mail: santosh4uma@yahoo.co.in

DOI: $10.14260 /$ jemds $/ 2019 / 489$
Traumatic epistaxis is most common in younger individuals and is most often due to digital trauma, facial injury or a foreign body in the nasal cavity.(4) Non traumatic epistaxis is more characteristic of older patients (Over age 50 years) and may be due to organ failure, neoplastic conditions, inflammation or environmental factors (Temperature, humidity, altitude).(4) Epistaxis occurring in younger individuals are usually mild and originates in anterior nose, whereas epistaxis of elderly is more likely to be severe and originate posteriorly. $(4,5)$ The treatment of epistaxis requires a systematic and methodological approach and option varies according to cause, location and severity of the haemorrhage. Both conservative and surgical approach has been used as the treatment modalities for epistaxis. (4)

Though there are large number of literatures on epistaxis from across the world and India but there are very few studies from the north eastern part of the country. Our study is unique as it is being carried out in population who lives in high altitude with tough climatic condition and may help us compute some unknown aetiology of epistaxis.

\section{Aims \& Objectives}

Determining the aetiology and outcome of conservative and surgical management of epistaxis. 


\section{METHODS}

\section{Study Type}

Hospital based cross sectional observational study.

\section{Study Setting}

The present study was conducted in the Department of ENT and Head and Neck Surgery, Department of Emergency Medicine.

\section{Ethical Clearance}

Institutional ethical clearance was taken prior to start of the study.

\section{Study Period}

Two months period from July -August 2018.

\section{Sample Size}

Due to time constrains the total number of patients included in our study was one hundred only (100).

\section{Definition of Case}

All patients reporting to ENT Out Patient Department (OPD) and casualty with epistaxis were included as cases.

\section{Data Collection}

After obtaining the informed written consent from the patient and in case of minor, consent from the parents, a meticulous examination of the patient was done. First priority was given to arrest the bleeding and to haemodynamically stabilize the patient. Once the patient is stabilized anterior rhinoscopy to localize the site of bleed, in case of anterior epistaxis and posterior rhinoscopy in case of posterior nasal bleed. Diagnostic nasal endoscopy was done in patient where site of bleeding was not localized on rhinoscopy. Other ENT diseases was also noted. A detailed history of the patient was taken to determine any previous episode of epistaxis with its aggravating and relieving factors, any co- morbidity the patient is suffering from with any long-term medication taken by patient will be noted. Routine biochemical and radiological investigation was carried out in selected cases if required. Specific investigations like Electrocardiography, Echocardiography was order if required by the patients. Interdepartmental referral was done.

The following data were noted down in the case record form-

- Patient's particulars.

- Type of epistaxis.

- Co-morbidity if present.

- Investigation.

- Treatment.

\section{Inclusion Criteria}

- Patients of all age group.

- Agree to give a voluntary consent.

- Suffer from epistaxis with or without co morbid diseases.

\section{Exclusion Criteria}

- Person who deny giving a voluntary consent.

- Haemodynamically unstable patients.

\section{RESULTS}

\begin{tabular}{|c|c|c|}
\hline $\begin{array}{c}\begin{array}{c}\text { Socio-Demographic } \\
\text { Variables }\end{array} \\
\end{array}$ & \begin{tabular}{|c|}
$\begin{array}{c}\text { Total Studied Population } \\
(\mathrm{N}=100)\end{array}$ \\
\end{tabular} & $\begin{array}{c}\text { Percentage } \\
(\%)\end{array}$ \\
\hline \multicolumn{3}{|l|}{ 1. Gender } \\
\hline (a) Male & 57 & 53.3 \\
\hline (b) Female & 43 & 40.2 \\
\hline \multicolumn{3}{|l|}{ 2. Age Group (years) } \\
\hline (a) $1-10$ years & 40 & 37.4 \\
\hline (b) $11-20$ years & 22 & 20.6 \\
\hline (c) 21 - 30 years & 16 & 15.0 \\
\hline (d) $31-40$ years & 10 & 9.3 \\
\hline (e) $41-50$ years & 5 & 4.7 \\
\hline (f) 51 and above & 7 & 6.5 \\
\hline \multicolumn{3}{|l|}{ 3. Religion } \\
\hline (a) Hindu & 73 & 68.2 \\
\hline (b) Christian & 5 & 4.7 \\
\hline (c) Muslim & 2 & 1.9 \\
\hline (d) Buddhist & 20 & 18.7 \\
\hline \multicolumn{3}{|l|}{ 4. Body temperature } \\
\hline (a) Febrile & 3 & 2.8 \\
\hline (b) Afebrile & 97 & 90.7 \\
\hline \multicolumn{3}{|l|}{ 5. Blood Pressure } \\
\hline (a) Normotensive & 80 & 74.8 \\
\hline (b) Pre-Hypertensive & 8 & 7.5 \\
\hline (c) Hypertension Grade I & 6 & 5.6 \\
\hline (d) Hypertension Grade II & 6 & 5.6 \\
\hline \multicolumn{3}{|c|}{ Table 1. Baseline Characteristics of The Population Studied } \\
\hline
\end{tabular}

\begin{tabular}{|c|c|c|c|c|c|c|c|c|}
\hline \multirow[b]{2}{*}{$\begin{array}{l}\text { Comparison } \\
\text { Parameters }\end{array}$} & \multicolumn{7}{|c|}{ Causes of Epistaxis } & \multirow[b]{2}{*}{$\chi^{2}, \mathbf{d f}, \mathbf{p}$} \\
\hline & 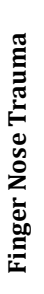 & 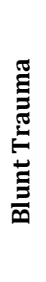 & 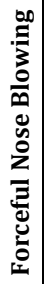 & 挀 & $\begin{array}{l}\tilde{y} \\
\frac{\pi}{0} \\
\frac{a}{2} \\
\dot{d} \\
z\end{array}$ & 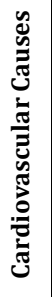 & 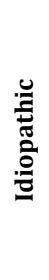 & \\
\hline \multicolumn{8}{|c|}{ 1. Number of Episodes of Nose Bleeding } & \multirow{5}{*}{$\begin{array}{c}\chi^{2}=17.845 \\
\mathrm{df}=18, \mathrm{p}=0.466\end{array}$} \\
\hline 1 Episode & 20 & 15 & 01 & 02 & 00 & 03 & 07 & \\
\hline $2-5$ Episode & 20 & 04 & 02 & 01 & 00 & 03 & 04 & \\
\hline 6-12 Episode & 05 & 01 & 01 & 01 & 01 & 02 & 01 & \\
\hline$>12$ Episode & 03 & 01 & 00 & 00 & 00 & 01 & 01 & \\
\hline \multicolumn{8}{|c|}{ 2. Blood Pressure of Patients } & \multirow{5}{*}{$\begin{array}{c}\chi^{2}=52.905, d f=18, \\
p=0.000^{*}\end{array}$} \\
\hline Normotensive & 45 & 19 & 03 & 03 & 01 & 00 & 09 & \\
\hline Pre- Hypertensive & 02 & 00 & 01 & 01 & 00 & 03 & 01 & \\
\hline Hypertension Grade I & 01 & 00 & 00 & 00 & 00 & 03 & 02 & \\
\hline \begin{tabular}{|l|} 
Hypertension Grade II \\
\end{tabular} & 00 & 02 & 00 & 00 & 00 & 03 & 01 & \\
\hline \multicolumn{8}{|c|}{ 3. Duration of Nose Bleeding } & \multirow{4}{*}{ 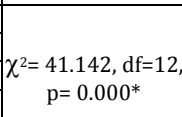 } \\
\hline$<1 \mathrm{~min}$. & 37 & 13 & 01 & 02 & 00 & 03 & 05 & \\
\hline $1-10 \mathrm{~min}$. & 11 & 08 & 03 & 02 & 00 & 04 & 06 & \\
\hline$>10 \mathrm{~min}$ & 00 & 00 & 00 & 00 & 01 & 02 & 02 & \\
\hline \multicolumn{8}{|c|}{ 4. Nostril Involved } & \multirow{4}{*}{$\begin{array}{c}\chi^{2}=10.752, d f=12, \\
p=0.55\end{array}$} \\
\hline Right Nostril & 22 & 08 & 01 & 03 & 00 & 03 & 06 & \\
\hline Left Nostril & 15 & 05 & 02 & 01 & 00 & 03 & 06 & \\
\hline Both Nostril & 11 & 08 & \begin{tabular}{|l|}
01 \\
\end{tabular} & 00 & \begin{tabular}{|l|}
01 \\
\end{tabular} & 03 & 01 & \\
\hline \multicolumn{8}{|c|}{ 5. Site of Nasal Bleed } & \multirow{4}{*}{$\begin{array}{c}\chi^{2}=64.88, \mathrm{df}=12 \\
\mathrm{p}=0.000^{*}\end{array}$} \\
\hline Little's area & 45 & 11 & 04 & 03 & 01 & 01 & 06 & \\
\hline Woodruff's Plexus & 01 & 01 & 00 & 00 & 00 & 06 & 01 & \\
\hline Lateral wall & 02 & 09 & 00 & 01 & 00 & 02 & 06 & \\
\hline \multicolumn{8}{|c|}{ 6. Associated ENT Problems } & \multirow{5}{*}{$\begin{array}{c}\chi^{2}=13.29, \mathrm{df}=18 \\
\mathrm{p}=0.774\end{array}$} \\
\hline DNS* & 02 & 00 & 01 & 01 & 00 & 02 & 01 & \\
\hline Nasal Vestibulitis & 01 & 00 & 00 & 00 & 00 & 00 & 00 & \\
\hline Rhinitis & 06 & 02 & 00 & 01 & 00 & 00 & 02 & \\
\hline None & 39 & 19 & 03 & 02 & 01 & 07 & 10 & \\
\hline 7. Seasonal & Corre & lation & with & Nose & Blee & & & \\
\hline Yes & 04 & 01 & 01 & 00 & 00 & 01 & 01 & $\chi^{2}=2.43, \mathrm{df}=6$ \\
\hline No & 44 & 20 & 03 & 04 & 01 & 08 & 12 & \\
\hline 8. A & ciatec & Mec & cal Pr & oble & & & & \\
\hline Hypertension & 01 & 00 & 00 & 01 & 00 & 06 & 01 & \\
\hline Diabetes Mellitus & 01 & 00 & 00 & 00 & 00 & 00 & 00 & $\mathrm{X}^{2}=57.85, \mathrm{df}=24$ \\
\hline Menorrhagia & 00 & 00 & 00 & 00 & 00 & 00 & 01 & \\
\hline CKD* & 00 & 00 & 00 & 00 & 00 & 00 & 01 & \\
\hline None & 46 & 21 & 04 & 03 & 01 & 03 & 10 & \\
\hline 9. Type of Inter & entio & n to $\mathrm{C}$ & ntro & Nas & I Ble & ding & & \\
\hline Conservative & 44 & 17 & 03 & 04 & 00 & 03 & 09 & \\
\hline Anterior nasal packing & 01 & 02 & 00 & 00 & 01 & 04 & 03 & $\chi^{2}=48.33, \mathrm{df}=2$ \\
\hline TCA Cauterization* & 02 & 02 & 00 & 00 & 00 & 02 & 00 & $p=0.002^{*}$ \\
\hline \begin{tabular}{|l|} 
Electro- cauterization \\
\end{tabular} & 00 & 00 & 01 & 00 & 00 & 00 & 01 & \\
\hline Septoplasty & 01 & 00 & 00 & 00 & 00 & 00 & 00 & \\
\hline Table 2. Comp & sono & $\overline{\text { Caus }}$ & sof & Epistc & is $w$ & th $\mathrm{Va}$ & ious & arameters \\
\hline $\begin{array}{l}\text { "DNS: Deviated Nasal } \\
\text { Acid }\end{array}$ & ntum & KD. & & i & ney & & & \\
\hline Compar & & & & dy $P$ & & & & \\
\hline
\end{tabular}




\begin{tabular}{|c|c|c|c|c|c|c|c|}
\hline Parameters & \begin{tabular}{|c|}
$1-10$ \\
Years
\end{tabular} & \begin{tabular}{|l|}
$11-20$ \\
Years
\end{tabular} & $\begin{array}{l}21-30 \\
\text { Years }\end{array}$ & $\begin{array}{l}31-40 \\
\text { Years }\end{array}$ & \begin{tabular}{|l|}
$41-50$ \\
Years
\end{tabular} & $\begin{array}{c}51 \& \\
\text { above }\end{array}$ & $\chi^{2}, \mathbf{d f}, \mathbf{p}$ \\
\hline \multicolumn{7}{|c|}{ 1. Cause of Epistaxis } & \multirow{8}{*}{$\begin{array}{c}x^{2}=93.870 \\
d f=30 \\
p=0.000^{*}\end{array}$} \\
\hline $\begin{array}{c}\text { Finger nose } \\
\text { trauma }\end{array}$ & 29 & 10 & 05 & 03 & 00 & 01 & \\
\hline Blunt trauma & 08 & 06 & 06 & 01 & 00 & 00 & \\
\hline $\begin{array}{c}\text { Forceful nose } \\
\text { blowing }\end{array}$ & 00 & 01 & 02 & 01 & 00 & 00 & \\
\hline DNS* & 01 & 01 & 00 & 01 & 01 & 00 & \\
\hline Neoplasm & 00 & 00 & 00 & 00 & 01 & 00 & \\
\hline $\begin{array}{l}\text { Cardiovascular } \\
\text { cause (HTN)* }\end{array}$ & 00 & 00 & 00 & 02 & 02 & 05 & \\
\hline Idiopathic & 02 & 04 & 03 & 02 & 01 & 01 & \\
\hline \multicolumn{7}{|c|}{ 2. Site of Nasal Bleeding } & \multirow{4}{*}{$\begin{array}{c}\mathrm{x}^{2}=39.152 \\
\mathrm{~d}=10 \\
\mathrm{p}=.000^{*}\end{array}$} \\
\hline Little's Area & 37 & 15 & 10 & 06 & 02 & 01 & \\
\hline $\begin{array}{l}\text { Woodruff's } \\
\text { Plexus } \\
\end{array}$ & 01 & 00 & 01 & 02 & 01 & 04 & \\
\hline Lateral wall & 02 & 07 & 05 & 02 & 02 & 02 & \\
\hline \multicolumn{7}{|c|}{ 3. Type of Epistaxis } & \multirow{4}{*}{$\begin{array}{c}\mathrm{x}^{2}=51.748 \\
\mathrm{~d}=10 \\
\mathrm{p}=.000^{*}\end{array}$} \\
\hline $\begin{array}{l}\text { Anterior } \\
\text { Epistaxis }\end{array}$ & 38 & 20 & 12 & 08 & 02 & 02 & \\
\hline $\begin{array}{l}\text { Posterior } \\
\text { Epistaxis } \\
\end{array}$ & 00 & 00 & 01 & 02 & 03 & 05 & \\
\hline Idiopathic & 02 & 02 & 03 & 00 & 00 & 00 & \\
\hline \multicolumn{8}{|c|}{ Table 3. Comparison of Age of Patients with Various Parameters } \\
\hline
\end{tabular}

\begin{tabular}{|c|c|c|c|c|c|c|}
\hline \multirow[b]{2}{*}{$\begin{array}{c}\text { Comparison } \\
\text { Parameter }\end{array}$} & \multicolumn{5}{|c|}{ Type of Intervention to stop Nasal bleeding } & \multirow[b]{2}{*}{$\chi^{2}, \mathbf{d f}, \mathbf{p}$} \\
\hline & 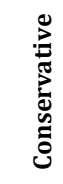 & 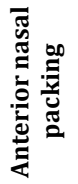 & ن & 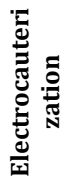 & $\begin{array}{l}\frac{3}{2} \\
\frac{\pi}{2} \\
\frac{2}{0} \\
\frac{\overrightarrow{2}}{2} \\
\dot{n}\end{array}$ & \\
\hline \multicolumn{6}{|c|}{ 1. Duration of each episode of nose bleeding } & \multirow{4}{*}{$\begin{array}{c}\mathrm{x}^{2}=36.431 \\
\mathrm{~d}=8 \\
\mathrm{p}=.000^{*}\end{array}$} \\
\hline$<1$ minute & 56 & 03 & 02 & 00 & 00 & \\
\hline $1-10$ minute & 23 & 04 & 04 & 02 & 01 & \\
\hline$>10$ minutes & 01 & 04 & 00 & 00 & 00 & \\
\hline \multicolumn{6}{|c|}{ 2. Number of each episode of nose bleeding } & \multirow{5}{*}{$\begin{array}{c}\mathrm{x}^{2}=10.329 \\
\mathrm{df}=12 \\
\mathrm{p}=.587\end{array}$} \\
\hline 1 episode & 38 & 06 & 03 & 00 & 01 & \\
\hline $2-5$ episode & 30 & 02 & 01 & 01 & 00 & \\
\hline $6-12$ episode & 07 & 02 & 02 & 01 & 00 & \\
\hline$>12$ episode & 05 & 01 & 00 & 00 & 00 & \\
\hline \multicolumn{6}{|c|}{ 3. Site of epistaxis } & \multirow{4}{*}{$\begin{array}{c}\mathrm{x}^{2}=15.984 \\
\mathrm{df}=8 \\
\mathrm{p}=.043^{*}\end{array}$} \\
\hline Little's Area & 61 & 04 & 04 & 01 & 01 & \\
\hline $\begin{array}{l}\text { Woodruff's } \\
\text { plexus }\end{array}$ & 04 & 03 & 02 & 00 & 00 & \\
\hline Lateral wall & 15 & 04 & 00 & 01 & 00 & \\
\hline \multicolumn{7}{|c|}{$\begin{array}{c}\text { Table 4. Comparison of Type of Intervention to Stop Nose Bleeding } \\
\text { with Various Parameters }\end{array}$} \\
\hline
\end{tabular}

\begin{tabular}{|c|c|c|c|c|c|}
\hline \multirow{2}{*}{$\begin{array}{c}\text { Duration } \\
\text { of each } \\
\text { Episode }\end{array}$} & $\begin{array}{c}\text { Deranged } \\
\text { CBC }\end{array}$ & $\begin{array}{c}\text { Deranged } \\
\text { LFT }\end{array}$ & $\begin{array}{c}\text { Deranged } \\
\text { Coagulation } \\
\text { Profile }\end{array}$ & $\begin{array}{c}\text { Normal } \\
\text { Study }\end{array}$ & \multirow{2}{*}{$\mathrm{x}^{2}, \mathbf{d f}, \mathbf{p}$} \\
\cline { 2 - 5 } \cline { 3 - 5 } & 5 & 3 & 1 & 52 & $\mathrm{df}=6.911$ \\
\hline$<1$ minute & 5 & 4 & 0 & 29 & \\
\hline $1-10$ mins & 1 & 0 & 0 & 5 & \\
\hline$>10$ mins & 0 & 0 & 0.99 \\
\hline Table 5. Comparison of Duration of Each Episode of Nasal Bleeding \\
with Laboratory Investigations \\
\hline
\end{tabular}

In table 1: baseline characteristics of study population shows that male 57 (53.3\%) were more than female 43 $(40.3 \%)$. Epistaxis occurred maximum in the age group of 1 10 years (37.4\%) and least in 41-50 years (4.7\%). Maximum number of patients belonged to Hindu religion (68.2\%) and only $2(1.9 \%)$ were Muslim. $90.7 \%$ of the patients were afebrile and most of the patients were normotensive $(74.8 \%)$

The major cause of epistaxis observed in this study was due to finger nose trauma occurring in 48 patients followed by blunt trauma in 21 patients and least being neoplasm that was in just 1 patient. Table 2: shows comparison of cause of epistaxis with various parameter such as number of episode, duration of nose bleeding, site of nose bleeding etc. where we find that the frequency of nose bleeding when compared with cause of epistaxis 1 episode or 2-5 episode occurred in maximum patients with finger nose trauma being commonly found in 40 patients, with duration of each episode being less than 1 minute in maximum patients ie., 37, finger nose trauma was commonly present from right nostril and involving little's area as the common cause was finger nose trauma so it is seen that majority of patients were normotensive. when we tried to compare the cause of epistaxis with associated ENT conditions, we found that there was no associated ENT or other medical condition which lead to finger nose trauma. There was no seasonal correlation with nasal bleeding. As the majority of patient had epistaxis due to finger nose trauma so majority were managed conservatively.

Table 3: shows comparison of age of the study population with various parameter where we can see that majority of the patient had finger nose trauma as most common complaint of nose bleeding with majority belonging to the age group if 1 10 years. with little's area as the common site of nose bleeding.

Table 4: shows the type of intervention to control nose bleeding with various parameter where we see that majority of patient with little's area as the site of epistaxis were managed conservatively.

Table 5: Comparison of Duration of Each Episode of Nasal Bleeding with Laboratory Investigations shows that maximum patients had normal laboratory findings - 86 patients. 6 patients with deranged CBC bled for $<1$ minute each episode and 4 patients with deranged LFT bled for 1-10 minutes each episode.

\section{Data Analysis}

The data obtained was sorted and categorized on the basis of demographic characteristics (Gender and age), diagnosis, investigations ordered, conservative and surgical treatment administered. The information was compiled and analysed by using SPSS (Statistical Package for the Social Sciences) version 16.00. The ' $p$ ' value was obtained using chi-square test and the results are depicted in the form of tables.

\section{DISCUSSION}

Our study is a prospective cross -sectional study conducted in Department of ENT and Department of Emergency Medicine, conducted for a short period of two months where 100 patients presenting to the departments of ENT and Casualty of our hospital with epistaxis and who gave informed consent to participate in our study were included. Out of 100 patients $57 \%$ were male and $43 \%$ were female which indicates that epistaxis was common in male patients in our study. Our finding is similar to various other study, Newton E et al(6) in their study of outcome analysis of anterior epistaxis and its management found the rate of epistaxis to be higher among men than women. Secchi MMD et al(7) in their study of prevailing factors and treatment of epistaxis also found epistaxis to be more common in men than women.

Various other study conducted by Gilyoma JM et al,(8) Ayad AS, Al-Azzaawi et al(9) also found the similar results as our study. Another parameter which was computed in our study is the age group of the patients presenting to the hospital with epistaxis where we saw that the majority of our study population was in the age group of 1-10 years which comprised of $40 \%$ of the total case followed by $22 \%$ in the age group of 11-20 years. The world over literature states that the prevalence of epistaxis is bimodal. Two peaks are noted in children younger than 10 years of age and in adults over the 
age of 40 years.(10) Our study showed that $40 \%$ of the study population was below 10 years and only $12 \%$ were above 40 years which partially justifies the world literature. The study conducted by Secchi MMD et al(7) showed different results where they found the maximum age of occurrences was 11-20 years of age. Similarly, study conducted by Khan MI et al(11) found mean age of occurrences of epistaxis was 38 years. In our study when we divided the patients as per their religion, we found that majority of them belong to Hindu $(73 \%)$ religion followed by Buddhist (20\%), Christian (5\%) and Muslim (2\%). In a similar study conducted by Varshney $\mathrm{S}$ et al(12) in Dehradun on 88 patients they found Hindu comprised of $78 \%$ of the study population followed by Muslim and Christian. This similarity must be as a result of both this study was done in Hindu dominated region and the result is not by chance.

We also divided the patients on the basis of body temperature at the time of epistaxis into febrile and afebrile where we found that majority were afebrile (97\%) at the time of epistaxis which indicate that they were not suffering from any acute infective condition during the time of epistaxis which could have caused the nasal bleeding. we also tried to divide the patients based on their blood pressure at the time of presentation but surprisingly majority of them were normotensive (80\%) at the time of presentation and only $12 \%$ were diagnosed hypertensive.

In our study we have computed various parameter and tried to compare them with each other. The various cause of epistaxis which we computed are Trauma both including finger nose trauma and blunt trauma which is the major cause for epistaxis in our study and it comprises $73 \%$ of our study population. The second most common cause was idiopathic where the cause for nose bleeding could not be found which comprised of $13 \%$ cardiovascular cause mostly hypertension for nasal bleed was seen only in $9 \%$ of the cases. Our finding is similar to the study conducted by Khan MI et al(11) where they studied 275 patients with trauma being the commonest cause in their study. In a similar study conducted by Al-Azzawi et al ${ }^{(9)}$ on 210 patients, trauma was the commonest cause followed by hypertension. The reason behind trauma being the commonest cause for epistaxis in our study and these studies are because in all these studies, males were affected more and majority belonged to younger age group. In our study finger nose trauma was seen in 48 patients and this can be justified by comparing it with the age as in our study majority were below 10 years of age.

The first comparison which we had done was between the cause of epistaxis and number of episodes of nose bleeding where we found that Finger Nose Trauma was the common cause and it led to recurrent nose bleeding in 28 patients followed by single episode of nose bleeding in 20 patients. However, this similarity was not by chance as the likely possibility of nose bleeding increases with recurrent nose picking hence the comparison is not statistically significant. $(\mathrm{P}=0.466)$. Another comparison which we tried to make was between the cause of epistaxis and duration of nose bleeding, Where we found that in 61 patient the nasal bleeding lasted only for a period of less than 1 minute, in 34 patients the bleeding lasted for around 10 minutes and only 5 patients had bleeding more than 10 minutes. This finding can be justified by analysing the cause where we saw that in majority of the patient the cause of nose bleeding was trauma (69) where finger nose trauma was seen in 48 patients, This can be justified by saying that the trauma is a acute condition and not due to systemic illness such as blood disorder hence in majority of the patients bleeding lasted for less than a minute, if bleeding lasted for more than a minute it is merely by chance hence the comparison is statistically significant $(\mathrm{p}=.000)$

We also tried to compare the cause of epistaxis with the nostril involved where we found that 43 patients had bleeding from right nostril followed by 32 patients from left nostril and 25 patients with bleeding from both nostril, however when we compared it with the cause of nose bleeding the $p$ value was not significant as bleeding from nostril is dependent on the dominance of hand of the individual as well as the site of pathology and majority of the subject in our study were right hand dominant. In Table 5 we have compared the cause of epistaxis with the blood pressure of the patients where we found that 80 patients with various cause of epistaxis were non hypertensive, 8 patients were pre-hypertensive, 6 each were grade 1 and grade 2 hypertensive respectively. Out of 12 hypertensive 3 had nasal bleeding because of trauma and the diagnosis of hypertension in them was by chance rest of the 9 hypertensives were a diagnosed case of hypertension and the bleeding from their nose is because of the cardiovascular condition and the comparison was statistically significant. $(p=0.000)$. Anie et al(13) had a similar finding in their study where majority of case of epistaxis was because of blunt trauma followed by $11.8 \%$ because of hypertension and the finding was statistically significant.

The cause of epistaxis was also compared with site of bleed; in which we noticed that finger nose trauma which is the major cause of nose bleed was from Little's area in 45 patients out of 71 with bleeding from little's area; and the result was very significant $(\mathrm{p}=.000)$. The reason for which being Little's area location in the anterior inferior part of the nasal septum being a very easy location to scratch and bleeding to occur. This comparison also shows that patients with hypertension, their site of bleed was found to be Woodruff's Plexus. Being a systemic condition??

Cause of epistaxis was also compared with other ENT problems in which it was noted that majority of the patients did not have any other ENT problems. Though 6 patients did have rhinitis and suffered nose bleeding because of finger nose trauma, for which the reason might be due to nose blockage and causing irritation to the patient. However, this comparison is not statistically significant $(p=.744)$. We also tried to compare the cause of epistaxis with seasonal correlation however in our study we did not find any seasonal correlation which is in contradiction to the study conducted by Varshney et al (12) where they found epistaxis to be common in the months of January to March. The reason for this difference is our study is a short-term study conducted for two months where we could not take all the four season into account so hence the difference.

We also tried to compare the cause of epistaxis with any other medical condition where we found only 11 patients to be suffering from other medical condition out of which Hypertension was seen in 9 patients with diabetes Menorrhagia and chronic kidney disease only in 1 each patient. Majority did not have any associated medical problem. Many other studies conducted by Anie et al,(13) Sinha BK et al(14) found Hypertension as one of the common causes for epistaxis after trauma which is as per the world literature. 
We also tried to compare the cause of epistaxis with type of intervention used in the patients with epistaxis which showed that conservative method of treatment which includes counseling with local nasal drops and ointment was effective in managing in 80 patients with epistaxis. Among these 44 patients had finger nose trauma as the primary cause so counseling to avoid nose picking was effective. Only 11 patients required anterior nasal packing with 6 requiring TCA cauterization of the nasal septum and 2 requiring electrocauterization with only 1 requiring septoplasty. The management protocol of our study was as per the standard protocol $(p=0.002)$. In a study conducted by Shah WA et al $(4)$ on 114 patients, non-surgical methods were main intervention method in $99 \%$ of the cases, the results of which is similar to our study.

On comparing age with cause of epistaxis we found that the cause of nose bleeding in younger age group was due to trauma in 62 patients out of which 40 were below 10 years and rest 22 were in the age group of 11-20 years. 14 patients had other cause for nose bleeding and majority had Hypertension and neoplasm as the common cause these group of patients are those above 30 years. The result was statistically significant $(0.000)$ as it is similar to the standard literature. As a study conducted by Shah WA et al(4) states that Traumatic epistaxis is most common in younger individuals and is most often due to digital trauma, facial injury or a foreign body in the nasal cavity. Non traumatic epistaxis is more characteristic of older patients (Over age 50 years) and may be due to organ failure, neoplastic conditions, inflammation or environmental factors (Temperature, humidity, altitude). Thus, our finding relates to the standard literature. We also tried to compare the duration of each episode of nose bleeding with laboratory investigation, but no significant result was obtained. On comparing the age with site of bleeding we obtained significant result as younger age had bleeding form little's area and more the age the higher chance of posterior nasal bleeding which is as per the present literature. In total 71 patients had epistaxis from little's area out of which 61 were managed conservatively whereas out of 9 patients with posterior epistaxis 5 required intervention which clearly states that anterior epistaxis can be managed conservatively in majority of cases where as the chance of intervention is more if the bleeding is from posterior nasal cavity. $(\mathrm{p}=.043)$. lastly we also tried to compare the type of intervention with duration of bleeding and number of episode of nose bleeding where significant correlation was seen with the duration and no association with number of episode of nose bleeding, which means that irrespective of number of episode the type of intervention does not change significantly however type of intervention may change if the there is any coagulation abnormality.

\section{CONCLUSIONS}

Trauma was the most significant cause of nasal bleeding out of which finger nose trauma was the most common. Younger age group was the most commonly affected group of patients in our study. Majority of the patients in our study were managed conservatively, with only a few requiring interventions. However, there are various limitations to our study as the duration was just for 2 months; so, we just could take only those patients into consideration who presented to us during those two months. Due to this, we missed out many other patients who could have been included if there was no time limit. As Sikkim is a hilly state, seasonal variation of epistaxis could not be computed during the given time frame. We also have a lot of patients with systemic causes for nasal bleeding; however, those were missed due to time limit. The study population is very small, is restricted to just one hospital so the results cannot be generalized to the entire state. More such studies conducted for longer duration, involving all the medical centres within the state can be done to study the various causes and derive effective treatment protocols for its management.

\section{REFERENCES}

[1] Manickam A, Ghosh D, Saha J, et al. An etiopathological study on epistaxis in adult and its management. Bengal Journal of Otolaryngology and Head and Neck Surgery 2015;23(1):12-7.

[2] Swapna UP, Simla SR, Anjali R, et al. Endoscopic evaluation and treatment of epistaxis - a prospective study. International Journal of Medical Research and Review 2016;4(6):971-5.

[3] Melinte V, Musteata O, Sarafoleanu C. Epistaxis management- our point of view and literature review. Romanian Journal of Rhinology 2017;7(28):207-13.

[4] Shah WA, Amin P, Nazir F. Epistaxis- etiological profile and treatment outcome at a tertiary care centre. J of Evolution of Med and Dent Sci 2015;4(3):5204-10.

[5] Krajina A, Chrobok V. Radiological diagnosis and management of epistaxis. Cardiovasc Intervent Radiol 2014;37(1):26-36.

[6] Newton E, Lasso A, Petrcich W, et al. An outcome analysis of anterior epistaxis management in the emergency department. Journal of Otolaryngology Head \& Neck Surgery 2016;45:24.

[7] Secchi MMD, Indolfo MLP, Rabesquine MM, et al. Epistaxis: prevailing factors and treatment. Intl Arch Otorhinolaryngol 2009;13(4):381-5.

[8] Gilyoma JM, Chalya PL. Etiological profile and treatment outcome of epistaxis at a tertiary care hospital in Northwestern Tanzania: a prospective review of 104 cases. BMC Ear, Nose and Throat Disorders 2011;11:8.

[9] Al-Azzaawi AAS, Miteab RT, Al-Khafaji MA. Epistaxis etiology and management. The Iraqi Postgraduate Medical Journal 2014;13(2):230-4.

[10] Tikka T. The aetiology and management of epistaxis. Otolaryngology Online Journal 2016;6(2):104.

[11] Khan MI, Marwat M, Khattak RA. Causes and management of epistaxis at a district hospital. Rawal Medical Journal 2013;38(1):48-51.

[12] Varshney S, Saxena RK. Epistaxis: retrospective clinical study. Indian Journal of Otorhinolaryngology and Head and Neck Surgery 2005;57(2):125-9.

[13] Anie MT, Arjun GM, Andrews CJ, et al. Descriptive epidemiology of epistaxis in a tertiary care hospital. International Journal of Advances in Medicine 2015;2(3):255-9.

[14] Sinha BK, Birua C, Kumar D. A clinical study of etiopathogenesis and management of epistaxis. IOSR Journal of Dental and Medical Sciences 2017;16(1):4952 . 